\section{A CRIANÇA PORTADORA DE SOFRIMENTO PSÍQUICO ENQUANTO SUJEITO DE PESQUISA DO SEU PROCESSO DE ADOECER}

\author{
The Child With Psychological Distress as a Subject of Research \\ of Process of Becoming Ill
}

\author{
El Niño con Sufrimiento Psíquico en Cuanto Sujeto de \\ Investigación de su Proceso de Enfermar
}

\section{L'Enfant Porteur de Souffrance Psychique comme Sujet de Recherche de son Processus de Devenir Malade}

\begin{abstract}
Resumo
Esta pesquisa visou à compreensão da criança enquanto sujeito de pesquisa e agente do seu processo de adoecer. $\mathrm{O}$ sofrimento psíquico foi analisado à luz da psicanálise winnitottiana, através da Teoria do Amadurecimento Humano, a partir da qual foi discutida a importância do suporte familiar e do meio saudável para um desenvolvimento emocional que tenda à integração do indivíduo, sendo o sofrimento psíquico da criança gerado pela falha dessa estrutura. Os sujeitos foram dez crianças de 7 a 11 anos. O local escolhido corresponde ao primeiro CAPS infantil do estado do Ceará, que atende ao público infanto-juvenil de 67 bairros do município de Fortaleza. Foram feitas anotações dos diários de campo, entrevistas semiestruturadas com as crianças colaboradoras e levantamento documental dos prontuários, no período de agosto a dezembro de 2011. Os resultados encontrados apontam para a propriedade que as crianças têm de reconhecer e expressas suas formas diversas de vivenciarem o sofrimento psíquico: agressividade, mudanças de humor, queixas de ansiedade, dificuldades escolares, dificuldade de aceitação da realidade, estigma, violência doméstica e sexual. A relevância deste trabalho encontra-se na compreensão do sofrimento psíquico pela ótica de quem o vivencia, e na contribuição para com pesquisas futuras, pois há na literatura pouco material sobre o sofrimento psíquico da criança e que respeite o seu discurso. A importância também é dada pelo conhecimento fornecido, que pode facilitar a reorientação de melhores práticas profissionais e de políticas públicas voltadas para a saúde mental infantil.
\end{abstract}

Palavras-chave: criança; sofrimento psíquico; psicanálise; teoria winnicottiana; narrativas.

\section{Abstract}

This research aimed to understand the child as a research subject and agent of its process of becoming ill. The psychological distress was assessed in the light of Winnicott psychoanalysis, through the Theory of Human Aging, where the importance of family support and healthy environment for an emotional development which tends to the integration of the individual were discussed, and the psychological suffering of children is generated by the failure of this structure. The subjects were ten children aged from 7 to 11 years. The site chosen corresponds to the first child CAPS from the state of Ceará and attends children and adolescents from 67 neighbourhoods in Fortaleza. For this, notes from the field diary were taken, semi-structured interviews with children were carried out and documentary survey of the records in the period from August to December 2011 was conducted. The results point to the property that the children need to recognize and express their different ways of experiencing psychological distress such as: aggression, mood changes, complaints of anxiety, school difficulties, difficulty in accepting the reality, stigma, domestic and sexual violence. Finally, the relevance of this work lies in understanding the psychological distress
Artigo Original
1) Psicóloga, Assistente Social e Mestre em Saúde Pública (UFC).

2) Pediatra, Doutor em Epidemiologia (Universidade Federal de Pelotas - RS)

3) Filóloga, Mestre em Letras e Doutoranda em Letras - Inglês (Universidad de Santiago de Compostela)
Recebido em: 16/11/2011 Revisado em: 02/10/2014 Aceito em: 02/10/2014 
from the perspective of those who experience and the contribution to future research, because there is little material in the literature on the psychological distress of the child's and respecting their speech. The importance is also given as a knowledge that can facilitate the reorientation of best professional practices and public policies for children's mental health.

Keywords: child; psychological distress; psychoanalysis; winnicott; narratives.

\section{Resumen}

Esta investigación tuvo como objetivo comprender al niño en cuanto sujeto de investigación y agente de su proceso de enfermar. Se evaluó el sufrimiento psíquico a la luz de la teoría psicoanalítica de la maduración humana de Winnicott, a partir de la cual se discute la importancia para el desarrollo emocional del apoyo familiar y de un entorno saludable que tienda a la integración del individuo, siendo el sufrimiento psicológico de los niños, resultado del fracaso de esta estructura. Los sujetos fueron diez niños de entre 7 y 11 años. El lugar elegido corresponde al primer CAPS infantil del estado de Ceará que atiende a niños $y$ adolescentes de 67 barrios del municipio de Fortaleza. Se tomaron notas de los diarios de campo, se realizaron entrevistas semi-estructuradas con los niños y una búsqueda documental de los registros del periodo entre agosto y diciembre de 2011. Los resultados encontrados apuntan a la propiedad que los niños tienen de reconocer y expresar las distintas formas de experimentar el sufrimiento psíquico: agresividad, cambios de humor, quejas de la ansiedad, dificultades escolares, dificultad para aceptar la realidad, estigma, violencia doméstica y sexual. La relevancia de este trabajo radica en la comprensión del sufrimiento psíquico desde la perspectiva del que lo experimenta y la contribución a investigaciones futuras ya que hay poco material en la literatura sobre el sufrimiento psíquico del niño teniendo en cuenta su discurso. También es importante debido a que el conocimiento obtenido puede facilitar la reorientación y mejora de prácticas profesionales y políticas públicas para la salud mental infantil.

Palabras clave: niño; trastornos psicológicos; el psicoanálisis; winnicott; narrativas.

\section{Résumé}

Cette recherche a visé à comprendre l'enfant comme sujet de recherche et de l'agent de son processus de devenir malade. La souffrance psychologique a été évaluée à la lumière de la psychanalyse winnicottienne, à travers la théorie du vieillissement de l'être humain, à partir de laquelle on a discutté l'importance $d u$ soutien familial et d'ambience saine pour un développement émotionnelqui tend à l'intégration de l'individu, et la souffrance psychologique des enfants générés par l'échec de cette structure. Les sujets ont été dix enfants âgés de 7 à 11 ans. L'institut choisi pour fair cette recherche est le premier CAPS de l'enfant du État du Ceará et s'adresse aux enfants et aux adolescents de 67 quartiers de Fortaleza. Pour cela, les notes ont étées prises d'après les revues de champ, interviews semi-structurées avec les enfants et on a réalisé l'étude documentaire des dossiers des ces enfansts-là à la période d'août à décembre 2011. Les résultats soulignent la capacité des enfants de reconnaître et d'exprimer leurs différentes façons de vivre et de présenter la détresse psychologique : de l'agression, des changements d'humeur, des plaintes, de l'anxiété, des difficultés scolaires, des difficultés à accepter la réalité, la stigmatisation, la violence domestique et sexuelle. Enfin, la pertinence de ce travail réside dans la compréhension de la détresse psychologique, dans la perspective de ceux qui l'éprouvent, et la contribution à des recherches futures, car il y a peu de matériel dans la littérature sur la détresse psychologique de la parole de l'enfant en respectant les mêmes. L'importance de cet article est également par la connaissance acquise qui peut faciliter la réorientation des meilleures pratiques professionnelles et des politiques publiques pour la santé mentale des enfants.

Mots-clés: enfant; la détresse psychologique; psychanalyse; théorie winnicottienne; récits.

\section{Conversando Sobre a Criança e seu Processo Histórico}

Segundo Müller (2006), ainda que a criança tenha existido desde os primórdios da humanidade, o conceito de infância foi uma invenção histórica e social da Era Moderna. "Desde o momento da concepção, tem início nos seres humanos um processo de transformação que continuará até o final da vida" (Papalia \& Feldman, 2013, p. 36). Até a Idade Média, a criança só era percebida como tal até os sete anos de idade, aproximadamente. Após essa idade, poderia ser autônoma o suficiente e capaz de contribuir laboralmente com as despesas de casa, passando a ser considerada, a partir de então, como adulto jovem: "[...] a duração da infância era reduzida ao seu período mais frágil e [...] mal adquiria algum desembaraço físico, era logo misturada aos adultos e partilhava de seus trabalhos e jogos" (Ariès, 1981, p.10). Por ser considerada vulnerável a doenças e devido à alta mortandade, vivia no decurso de sua primeira infância, segundo Ariès (1981), no mais completo anonimato e exclusão sociofamiliar, chegando ao extremo de muitas vezes ser-lhe negada inclusão na contagem de membros da própria família; tampouco recebia qualquer tratamento diferenciado ou importância especial.

Conforme Müller (2006), até aproximadamente os seis primeiros anos, dada sua grande vulnerabilidade e imaturidade cognitiva e física, a criança era percebida como um fardo, e como tal, práticas de negligências, abusos e maus-tratos eram socialmente aceitas (dentre elas, o infanticídio, o abandono à própria sorte, violências das mais diversas naturezas - física, sexual e moral -, falta de alusão às mortes, incluindo neste contexto a falta de referência familiar e a falta de registro sobre sua idade). A partir dos sete anos, já passava a ser percebida como amadurecida, uma espécie de jovem adulto, uma vez que já conseguia ter 
a autonomia necessária para cuidar de si mesma de forma independente, tendo condição de suportar atribuições dos adultos como atividades laborais, de acordo com Papalia e Feldman (2013) e, com isso, contribuir concretamente para a manutenção da família.

Não apenas era-lhe permitido o acesso ao mundo do trabalho, como também ao espaço social. Conforme Ariès (1981), a sociedade se estruturava no espaço público, onde as relações se efetivavam e os costumes eram transmitidos, em sua maioria, através da oralidade, de forma empírica e informal. Basicamente, não havia privacidade e era muito natural a criança, na segunda infância, presenciar atos sexuais, insinuações e jogos eróticos, uma vez que, sendo considerada impúbere, estava isenta de malícia e indiferente às práticas sexuais adultas. No campo afetivo, as relações ternas geralmente aconteciam fora do contexto familiar, sendo comum a troca de carinho entre amigos, mas não havia o estreitamento afetivo nas relações entre pais e filhos.

Na realidade brasileira, já no começo da Era Moderna, segundo Del Priore (2000), as crianças índias e negras trabalhavam de modo exaustivo, mas a branca também era muito ocupada com atividades escolares e prendas socialmente aceitas. Tímidos a princípio, entre os séculos XV e XVII, houve uma percepção e um reconhecimento nunca antes destinados à criança pelos adultos. De fadada ao esquecimento, passou gradativamente a ter sua integridade física e moral preservadas, devido à expansão do movimento de cristianização dos costumes, colocando-se no patamar de ser com alma. Nesta nova condição, deveria ser freada nos seus impulsos sexuais e paixões de ordens diversas, de modo a ser assegurado o recém-criado estado de pureza infantil. Com os ideais iluministas, a criança passou gradativamente a ser percebida com uma subjetividade própria e demandas específicas à manutenção de sua existência.

Desta forma, de acesso irrestrito ao espaço público, a criança passou a ficar sutilmente reclusa no âmbito doméstico, para ser disciplinarizada, vigiada e, à luz de Foucault (1984), tornar-se dócil, moral e fisicamente controlada nos seus pudores, comportamentos e palavras. Essa docilidade foi moldada à custa de muito castigo físico e rigidez moral, como forma sutil de impor, segundo Rocha (2004), a grande mordaça do silêncio, o cárcere da negação de si enquanto sujeito portador de direitos e agente do próprio processo interno. Desta forma, a criança moderna adentrava fortemente no espaço privado cerceado pelas instituições Escola, Igreja e Família. No campo afetivo, segundo Cavalcante (2001), passou a receber um grau de atenção e afetividade nunca antes recebido, tornando-se emocionalmente mais pertencente e valorizada na família e socialmente.

Com a contemporaneidade, a sociedade, na ânsia de galgar novos ideais libertários, passa a creditar, gradativamente, valores ao discurso do sujeito na mais tenra idade. Da couraça de invisibilidade e exclusão de outrora, as últimas décadas proveram uma geração que é fruto de novas configurações familiares e com menor moralismo. Este é, por excelência, um campo fértil para o rompimento da lógica moderna de perceber o sujeito infantil pela ótica da candura. Ao invés desta visão minimalista e opressora, Müller (2006) aponta que a criança das décadas atuais está, cada vez mais, sendo estimulada a expressar seus anseios e demandas e criar a própria cultura, devido à possibilidade que tem de conhecer novas (e excessivas) informações disponíveis.

A criança, ao interagir com a realidade, consegue reinventá-la e produzir uma cultura particular e distinta da forma adulta de perceber e interagir com o meio. Segundo Corsaro e Miller (1992), que, ao construir a própria cultura, a criança passa a ser também construtora da realidade adulta hegemônica e, uma vez que tem função relevante no processo constituinte e transformador de realidades, merece ser ouvida em suas demandas. Rocha (2004) percebe a infância de modo heterogêneo, ou seja, não existe uma infância única, mas um somatório de infâncias, plural por excelência e amplo o bastante, que a coloca não como categoria em absoluto natural e universal, mas essencialmente como fruto de uma construção histórica e social.

A heterogeneidade do conceito é constituinte da possibilidade da autonomia geradora de cultura própria, da percepção e dotação de sentido da realidade que a cerca. Foucault (1996), a partir da noção de historicidade, compreende que a infância é uma construção histórica e social que vai sendo delineada a partir de culturas e épocas específicas, encontrando-se em constante processo de transformação. Portanto, não é natural nem universal e, principalmente, não é um fenômeno único, mas acima de tudo é ontológico. A criança vai construindo sua estrutura anímica através do discurso, por meio do qual emoções, interpretações e reelaboração de vivências são exteriorizadas, conforme indica Cavalcante (2001). E a partir de suas narrativas, o universo infantil vem à tona para maior e melhor compreensão pela ótica adultocêntrica.

Alderson (2005) aponta que ninguém é capaz de descrever melhor as vivências infantis do que quem a vivencia, e devido a isso, o discurso da criança precisa ser valorizado e validado, não apenas porque através dele há o processo de tessitura da própria singularidade, mas principalmente porque o reconhecimento da sua fala pelos adultos possibilita-lhe maior ganho de autonomia e fortaleza diante das formas sutis de violência que lhe negam o direito de ser sujeito, no sentido pleno do termo. 


\section{Contemporaneidade e Validação do Discurso Produzido pela Própria Criança: Novo Sujeito de Pesquisa}

Até pouco mais de meados do século XX, cabia ao adulto a responsabilidade de opinar sobre as condições, necessidades e desejos infantis, cabendo à criança, segundo Solon (2009), a esta última, a impotência e submissão à decisão adulta (por vezes arbitrária e descontextualizada do universo infantil). À criança era restrito o direito de expressar as próprias demandas, tornando-se objeto de si mesma, perdendo a autonomia sobre si e sobre seus processos subjetivos. Conforme Solon $(2009$, p. 21): “[...] à criança era reservada impotência e submissão à decisão adulta". A contemporaneidade trouxe consigo um reconhecimento nunca antes visto na história da humanidade. Pela primeira vez, a criança passou a ser percebida pelo adulto como um sujeito portador de voz, de cultura e de direitos próprios, assim como sujeito dos processos de pesquisa. Em especial nas décadas atuais, este cenário vem se modificando a partir de um movimento irreversível que vem dando espaço para a expressão da criança sobre si mesma, o que representa, sobretudo, segundo Alderson (2005), a saída da passividade para a condição de ser sujeito e narrador de suas próprias vivências e construtor de uma realidade própria e validada, possibilitando a quebra do discurso hegemônico adulto sobre a criança.

Este reconhecimento é fundamental para proteger a integridade da criança, uma vez que, sendo compreendida pela ótica do adulto, pode ficar mais vulnerável a formas de violência desde as mais sutis (como a negação da autonomia infantil) até as mais explícitas, conforme exposto por Rocha (2004). A criança, enquanto agente de transformação de sua própria cultura e vida social, é capaz de perceber e dar sentido às vivências e ao meio que a cercam no instante em que produz narrativas das experiências infantis, trazendo a realidade à sua compreensão. Portanto, segundo Delgado e Müller(2005) e Cavalcante (2001), deve ter sua subjetividade reconhecida pela lógica do adulto, porque ela é dona do seu processo interno e, através do discurso, vai gradativamente construindo sua vida psíquica, exteriorizando emoções, interpretando e ressignificando vivências próprias.

Bock, Furtado e Teixeira (2000) afirmam que os valores da criança vão sendo constituídos a partir dos modelos identificatórios dos adultos, mas que a criança vai desenvolvendo, segundo Delgado e Müller (2005), discursos e comportamentos singulares de tal maneira que, por ser criadora da própria cultura, esta não deve ser interpretada pela ótica adulta. Sarmento e Cerisara (2004) afirmam que o próprio pesquisador precisa se desnudar ao máximo de suas pré-noções universalistas, generalizantes e obviedades adultocêntricas.
Por tudo o que foi expresso, o discurso infantil tornase validado academicamente e a criança pode ser incluída como sujeito de pesquisa por ser plenamente capaz de produzir suas informações e vivências viáveis ao estudo sistemático e analítico da pesquisa científica, quebrando, com isto, não apenas o discurso hegemônico sobre ela como também possibilitando a sua passagem da passividade para a condição de ser sujeito e narrador de si.

\section{Método}

Este trabalho é o resultado de uma investigação acerca da percepção, vivência e enfrentamento do sofrimento psíquico infantil. Sua natureza é qualitativa e situada no campo da saúde mental. Os sujeitos foram 10 crianças usuárias do CAPSi Maria Ileuda Verçosa, instituição que faz parte do modelo nacional de assistência à saúde mental infanto-juvenil, atendendo à população proveniente de 67 bairros do município de Fortaleza, situados nos âmbitos das Secretarias Executivas Regionais II, IV e VI. A escolha da faixa etária da segunda infância, compreendida entre 07 e 11 anos, correspondeu à importância que damos (sem desmerecer as demais) à etapa do ciclo vital em quepensamento lógico das operações concretas possibilita, segundo Bock, Furtado e Teixeira (2000), maior domínio da linguagem. Além disso, Papalia e Feldman (2013, pp. 324327 ), apontam que este momento do ciclo vital é marcado por ganhos cognitivos consideráveis na compreensão de conceitos de causalidade, raciocínio indutivo e dedutivo, espacialidade, categorização, números e conservação, sendo possível fazer uso de operações mentais na resolução de situações concretas. A quantidade foi delimitada a partir da profundidade e saturação do tema, segundo Fontanella, Campos e Turato (2007).

Cada criança colaboradora teve a participação efetivada a partir do consentimento formal de suas responsáveis (quase sempre as mães). A adesão foi voluntária e sucedeuse ao conhecimento dos propósitos, instrumentos e metodologia do estudo através da assinatura do Termo de Consentimento Livre e Esclarecido (TCLE), sob o número COMEPE 214/2009. Por lidar com seres humanos, seguiu devidamente as recomendações bioéticas preconizadas pela Resolução 196/96 do Conselho Nacional de Saúde. Como uma forma de não identificar os colaboradores, segundo Kramer (2002), a fim de manter a preservação bioética do sigilo da identidade, próprio de pesquisa feita com seres humanos, cada sujeito foi reconhecido através de um pseudônimo por eles escolhido. No decurso do processo de entrevistas, foi sendo percebido que sonhos de realização profissional faziam parte do processo de enfrentamento do sofrimento psíquico deles e, desta forma, cada um foi identificado segundo seu desejo, surgindo, 
então, os seguintes colaboradores: o mecânico, o operador de gravação, o jogador de futebol, a advogada, o piloto, o policial, o professor, o médico, o pintor de quadros e a cantora.

Mesmo tendo por foco de estudo o discurso das crianças, o estudo ampliou o conhecimento sobre cada uma através de entrevistas feitas também com suas responsáveis e da análise minuciosa dos relatos dos profissionais através das evoluções de prontuários. Todo este material foi acrescentado à análise e serviu não apenas como um legitimador dos conteúdos relatados, mas também se transformou em valioso material complementar e agregador da compreensão sobre as vivências infantis do sofrimento psíquico. Como instrumentos para a coleta de dados, foram utilizados um diário de campo para apreensão dos aspectos verbais e não verbais das crianças e de suas respectivas responsáveis, entrevistas semiestruturadas, além de toda uma revisão minuciosa dos prontuários. Para Fontanella et al. (2007) e Minayo (2000), a entrevista semiestruturada tem a importância de fornecer dados primários e secundários, assim como possibilita ao pesquisador captar a espontaneidade, os sistemas de crenças e as singularidades vivenciadas pelos colaboradores.

Por fim, houve a revisão dos prontuários, que, conforme Câmara (2011), serviu para a ampliação do estudo de cada caso clínico, pela apreensão dos dados sociodemográficos, hipóteses ou diagnósticos já estabelecidos, conhecimento da história pregressa e evoluções da equipe multiprofissional. Finalmente, a metodologia utilizada para análise de dados foi o discurso das narrativas, segundo as ideias trabalhadas por Jovchelovitch e Bauer (2003) e Botelho, Janzen Kassab e Leite (2008), tendo por foco maior a captação de tessituras de singularidades e vivências socioculturais para melhor compreensão do sujeito sobre seu processo de adoecimento e ressignificação.

\section{Resultados e Discussão}

Os resultados foram obtidos a partir das construções simbólicas narradas pelos colaboradores. A validação da fala e interpretação da criança sobre si, de acordo com Delgado e Müller (2005) e Alderson (2005), foi o objetivo a ser alcançado, uma vez que a criança entende seu contexto subjetivo e processos patológicos vivenciados melhor do que qualquer interpretação adulta. Ratifica-se, no entanto, que o discurso das responsáveis e dos relatos profissionais foram estudados e acrescentados à análise apenas e tão somente como material complementar. Quanto ao público estudado, a partir dos prontuários, foi possível perceber, conforme Câmara (2011, p. 93), uma variada sintomatologia apresentada e diagnósticos:
[...] distúrbio de comportamento, distúrbio de aprendizagem, transtorno do déficit de aprendizagem e hiperatividade, histórico de epilepsia, transtorno emocional da infância, desvio de conduta, comportamento opositor/ desafiador, impulsividade, transtorno obsessivo compulsivo e transtorno afetivo bipolar. Como hipóteses diagnósticas, houve questionamentos para: depressão infantil com transtorno apontador, inteligência limítrofe ou baixa estimulação ou sintomas depressivos.

Winnicott (1997) aponta que a vivência de eventos traumáticos que promovem conflitos existenciais e/ou privações marcadas por abusos e negligências ocorridos no processo de amadurecimento emocional podem afetar o desenvolvimento psíquico do sujeito, assim como seu sentimento de pertença, autoestima e identidade. A partir dos discursos analisados, foi possível estruturar os modos de subjetivação das crianças frente a seus processos psicopatológicos, como veremos a seguir.

\section{Percepções do Sofrimento Psíquico}

A criança, no instante em que vai ultrapassando os estágios do processo de amadurecimento pessoal, passa, segundo Winnicott (1997), gradativa e progressivamente, a perceber e apropriar-se do sofrimento psíquico que vivencia, pois, conforme Torralba (2007), para que tal fenômeno aconteça, é necessário atingir um grau de maturidade suficiente para tornar-se cônscio não apenas de sua presença como também da sua intensidade. A percepção de ser portadora de sofrimento psíquico pode também ser marcada como o não reconhecimento de algo estigmatizante, pois muitas vezes estão ativados os mecanismos de defesas egoicas. Conforme Chvatal, Böttcher-Luiz e Turato (2009), tais estruturas do ego são utilizadas como mecanismos constituintes de saúde do aparelho psíquico e como estratégias para suportar a realidade, camuflando ou minimizando seus impactos através da negação, da racionalização, da projeção e de tantos outros mecanismos, visando mascarar e minimizar sentimentos emocionalmente densos de vergonha, raiva, vitimização, receio de rejeição e constrangimentos diversos.

Validando o que fora apontado na metodologia, cada sujeito primário foi identificado não pelas iniciais dos próprios nomes, mas pelas profissões que almejam desenvolver no futuro. Esse sonho foi percebido como estratégia de enfrentamento do sofrimento psíquico. Com relação aos colaboradores diretos, todos perceberam que são portadores de algum sofrimento subjetivo, no entanto, as maneiras, tanto de percepção quanto de vivências de tais dores anímicas, são singulares. Algumas crianças vivenciam-no através da vergonha e do sentimento de serem diferentes dos seus iguais, enquanto outras lidam com raiva, 
revolta ou medo:

Minha mãe diz que às vezes eu sou bom, só que tem vezes que eu sou, sou, [...], assim, como é que se diz, começo a me irritar com muitas coisas. [...] ... a minha avó foi quem teve a ideia de me trazer pra cá, porque antes quando eu não vinha pra cá, eu me irritava com qualquer coisinha, aí eu já ficava com raiva, com muita raiva aí minha avó teve a ideia de botar eu [sic] pro CAPS, para ver se eu ficava melhorzinho em casa. ("Médico" - criança colaboradora 08)

Eu sou assim. Eu não acho que eu sou diferente. Todo menino tem que ser danado mesmo. [...] eu adoro ir para o CAPS. Por mim, eu vinha todo dia. ("Médico" - criança colaboradora 08 )

Eu tenho é muita dor de cabeça e dor nos meus olhos, principalmente quando eu tento estudar. Aí é que piora. Eu sinto dor de cabeça quase todos os dias, mas a doutora disse que eu não tenho coisa séria, que eu tenho é que tomar os remédios para melhorar [...] Eu tenho muito medo. Tô [sic] vendo televisão e sinto uma agonia. Um homem fica dizendo para eu bater. Eu tenho medo e bato. Tem vezes que eu tento fugir para ver se eu escapo. ("Piloto" - criança colaboradora 05)

(Discurso confuso). Eu tenho revolta. [...] Eu fico revoltada, batendo nas coisas. (Silêncio). Fico com raiva, fico batendo nas coisas. (Silêncio) [...] eu sou agressiva. Quando eu tô [sic] com vontade de bater, eu só quero é bater. ("Advogada" - criança colaboradora 04)

\section{O Discurso Sobre a Vivência da Doença}

A vivência do sofrimento psíquico foi muito caracterizada nos sujeitos pela constância de um comportamento agressivo. A agressividade em si não é algo necessariamente ruim, pois, conforme Tommasi (1997) e Winnicott (1994), é através da agressividade que o bebê pode sair da postura passiva das experiências instintivas e destrutivas e entrar gradativamente em contato com o meio, para que possa atingir a integração e o amadurecimento emocional adequados. Conforme Winnicott (1994, p. 75): "O impulso construtivo está relacionado em parte com a aceitação pessoal da criança, da responsabilidade pelo aspecto destrutivo de sua natureza". A agressividade se manifestou pelos mais diversos motivos: insatisfações, não aceitação de realidades, desejos frustrados ou, em menor intensidade, foi desencadeada imotivadamente.

As narrativas das crianças estavam evidenciadas tanto pela autoagressividade quanto pela heteroagressividade e foram manifestadas por meio verbal e/ou físico através de atos diversos de rebeldia, desobediência, espírito de vingança, impulsividade dos instintos ou medo de sintomas psicóticos, medo de passar constrangimento familiar e social diante da falta de controle emocional a estímulos disparadores, rejeição parental que provoca o sentimento de não ser digno de amor e pertencente ao meio. Essas expressões agressivas constituíram uma forma, por elas encontradas de aliviarem sentimentos afetados:

Quando estou com raiva, tenho que bater na pessoa. ("Piloto" - criança colaboradora 05)

[...] se sente muito rejeitado pelo pai dele. Ele abraça o pai, beija o pai. O pai dele é menos carinhoso, pouco apegado a ele e meu filho sofre muito com isso. Tem vezes que eu acho que ele acaba descontando a carência que sente pelo pai dele, sendo muito agressivo. Ele só tem um amigo e às vezes nem isso, porque ele é muito agressivo mesmo. (Relato complementar da responsável de "Mecânico" criança colaboradora 01)

Eu bato nela, na minha irmã. A minha mãe gosta mais dela. Eu brigo, brinco... ("Advogada" - criança colaboradora 04)

Eu tenho muito medo de explodir na frente das pessoas. Eu não consigo controlar e depois eu fico mesmo é querendo me esconder, porque é muito ruim. Quando eu explodo, eu me sinto muito mal, com vergonha, com pena. ("Médico" - criança colaboradora 08)

O comportamento socialmente indesejado foi narrado em vários momentos. Para Winnicott (1994), a tendência antissocial é uma característica que todo sujeito (psiquicamente comprometido ou não) pode desenvolver, e que não surge espontaneamente, mas é fruto de uma construção social de privações e negligências por um período suficiente o bastante para provocar impactos negativos para o psiquismo do sujeito. A tendência antissocial apresentada pelas crianças evidenciou três aspectos: comportamentos de furto, oposição/desafio e mentiras. Estes comportamentos se manifestaram como uma maneira de chamar a atenção de terceiros, de limitações afetivas, escolares e financeiras ou mesmo diante da intolerância à frustração:

[...] a minha mãe não quis me dar o jogo, aí eu fiquei chorando na loja e disse que eu ia morrer se ela não me desse. Ela brigou comigo e eu me machuquei. ("Policial" - criança colaboradora 06)

No exemplo a seguir, quando a criança foi perguntada sobre o porquê de ser acompanhada no CAPSi, respondeu: 
[...] porque eu sou acompanhado, porque eu mexo nas coisas em casa. (Cabeça baixa) [...] Ficar tirando [...] Eu pedi à minha mãe e ela não me dá por... (Pausa) [...] Aí eu queria comprar alguma coisa para eu comer antes de ir para a igreja, mas ela não deixava... ("Jogador de Futebol" - criança colaboradora 03)

Um fenômeno traumático e impactante diz respeito tanto à violência física quanto à sexual. Esta vivência é, segundo Albornoz e Nunes (2004), tão deletéria que provoca no sujeito dificuldades adaptativas e afetações nas interações pessoais, escolares, sociais e familiares, além de ser permeada, sobretudo, pelo grande sentimento de desamparo. Para Laplanche e Pontalis (1992), o trauma equivale ao comportamento de não reação a um evento indesejável e intenso o bastante, que não dá a possibilidade para quem o vivencia de esquivar-se ou reagir e que, com o decurso do tempo, promove uma ruptura na homeostase emocional assim, como perda de confiança com o meio.

Dois colaboradores sofreram violência direta: agressões físicas e abusos morais da genitora e abuso sexual causado por um vizinho idoso. Conforme Soares, Moreira, Monteiro e Fonseca (2005), algumas famílias acreditam que suas crianças são propriedades suas e, como tais, cabe à família o controle e as imposições de castigos como algo naturalizado. No caso do primeiro sujeito, diante de tamanha violência, os próprios vizinhos fizeram denúncia das agressões para o Conselho Tutelar e para o Disk Denúncia da Criança e do Adolescente. Ficou patente na entrevista que a criança acredita ser merecedora da irascividade materna, visto que não se considera bom filho o bastante para a mãe.

Eu acho que a minha mãe me bate porque eu mereço, porque eu não faço direito o que ela manda. Às vezes eu acho que ela bate muito forte. ("Jogador de Futebol" criança colaboradora 03 )

Quanto à segunda criança, segundo relatos do prontuário, a mãe começou a perceber que o filho estava muito estranho e triste, e só compreendeu o acontecido quando o menino mencionou, durante um pesadelo, ideias desconexas. Conforme Gabel (1997), o silêncio causado pelo medo, vergonha ou falta de consciência exata sobre a magnitude da violência sofrida ainda é o grande mantenedor de tal realidade transgressora e por demais invasiva, promotora de intenso sofrimento anímico. Esta última criança não mencionou de forma alguma o acontecido, usando como mecanismo de defesa a negação como forma de suportar essa realidade aviltante e agressão psíquica extrema, compreendendo o que aconteceu como um castigo pelo seu constante comportamento inquieto e travesso:
Eu fui notando que ele estava diferente, muito isolado, chorando e perguntava para ele: "Meu filho, conta pra mamãe o que foi que aconteceu?" Mas ele não dizia. Inventava outra estória e não me respondia. Aí ele começou a ter pesadelos e numa noite ele ficou falando enquanto dormia: "Bota não, tá ardendo. Tá ardendo o meu bumbum". Foi aí que eu quase fiquei louca e entendi o que tinha acontecido (Relato complementar da responsável de "Operador de Gravação" - criança colaboradora 02)

\section{Mudanças de Humor}

Várias foram as menções a expressões anímicas próprias de quadros de mudanças de humor, entre as quais podemos mencionar: choro fácil, anedonia, embotamento emocional, irascividade imotivada e limitações no trato interpessoal. Conforme Antonio (2006, p. 95): “[...] o sofrimento subjetivo se manifesta sob forma de sintomas narcísicos e depressivos, em indivíduos que cada vez mais [...] têm dificuldades para articular numa narrativa as próprias histórias, vivências e dores".

O sintoma mais prevalente nos discursos foi 0 sentimento de tristeza intensa. Torralba (2007) afirma que a citada dor emocional traz consigo o forte sentimento de culpa inerente ao processo de amadurecimento emocional, conforme Winnicott (1990). Enquanto fenômeno doloroso e crucial, é disparador de embotamento afetivo, apatia e afetação da rotina pessoal, social, escolar, acadêmica e/ou laboral. Conforme Câmara (2011), sua ativação no sujeito é dada tanto pela interiorização quanto pela imaginação e é vivenciada de modo atemporal:

Às vezes eu sinto uma tristeza e aí eu não quero conversar, não. É muito ruim. Eu quero só ficar na minha cama, sem ter vontade de sair. Aí me dá uma vontade de chorar, mas eu não consigo. É ruim. ("Piloto" - criança colaboradora 05)

Eu fuinotando que meu filho foi mudando o comportamento dele. Ele foi deixando de ficar como as outras crianças, foi se isolando de todo mundo. Eu comecei a achar aquilo estranho, principalmente por ele não querer mais brincar e isso não é esperado para uma criança. [...] Eu noto que ele tá [sic] entrando em uma nova crise quando começa a chorar do nada, a quebrar as coisas dentro de casa e empurrar os irmãos. [...] Eu sofro muito com a doença do meu filho. Ver que ele é tão diferente dos outros meninos, com tanta dificuldade de aprendizado. Já é a segunda vez que ele repete de ano. Ele fica se sentindo tão mal e eu fico triste de ver meu filho assim. (Relato complementar da responsável de "Professor" - criança colaboradora 07) 
A tristeza também foi manifestada pelo sentimento de baixa estima em não conseguir ter um comportamento desejado e pelas dificuldades escolares, devido, principalmente, à dificuldade para reter conteúdos, à inquietação, ao desânimo, à falta de concentração e aos conflitos internos:

[...] eu acho que eu não vou passar este ano. Eu não tenho condições, não consigo entender as coisas, aprender. Eu não tenho condição de ir para a terceira série. (Relato complementar da responsável de "Piloto" - criança colaboradora 05)

Meu filho nunca reprovou [sic], mas ele tem muita dificuldade para aprender. Eu pago $\mathrm{R} \$ 50,00$ para o reforço dele, para ver se entra mais alguma coisa na cabeça dele. De vez em quando ele me fala umas coisas que me deixam muito triste: "Oh, mãe, eu estudo, estudo, mas as coisas não entram na minha cabeça; não entram não. (Relato complementar da responsável de "Mecânico" - criança colaboradora 01)

\section{Estratégias de Enfrentamento do Sofrimento Psíquico}

As crianças colaboradoras da pesquisa deixaram patente em suas narrativas que, apesar de vivenciarem, ainda em tão tenra idade, formas diversas de limitações, estigmas e conflitos internos provocadores do estado de sofrimento psíquico, foram desenvolvendo estratégias de ressignificação de suas dores e tensões pautadas essencialmente no aspecto lúdico, como fonte de extravasamento de energias negativas e dolorosas.

Como a realidade do sofrimento psíquico é muito permeada por conteúdos negativos e dolorosos o bastante para serem vivenciados concretamente, muitas vezes os sonhos são estratégias criadas para suportar e realizar desejos que não podem ser vivenciados e que, conforme Fadiman e Frager (1994), contribuem para a saúde da organização psíquica, protegendo-a de lacunas e conflitos internos. Foi comum encontrar nas crianças colaboradoras a menção de narrativas pautadas na fantasia, muitas vezes interpretadas como mentiras pelos responsáveis, já bastante desgastados pela convivência com o sofrimento psíquico de suas crianças.

Entre os sonhos mais manifestados, têm-se: o desejo de se tornarem profissionais quando adultos e até mesmo de seguirem a mesma carreira paterna, de continuarem os estudos, de casarem, e terem filhos e uma convivência familiar feliz. Além disso, sonham em controlar comportamentos indesejados:
A escola é legal. Tirei 10,0 e 9,5. ("Mecânico" - criança colaboradora 01)

Quando eu tô triste, minha mãe me leva para passear, me leva pra praia. ("Jogador de Futebol" - criança colaboradora 03)

[...] Trabalhar... Ser alguém na vida. [...] Trabalhar com Mecânica. [...] (Difícil compreensão), é ganhar presente, eu sonho em ter um carro. [...] Eu quero um novo! É... carro de luxo. ("Mecânico" - criança colaboradora 01)

[...] Casar, ser policial, fazer uma tatuagem [...] Do dragão, porque eu acho bonita. ("Policial" - criança colaboradora 06)

A coisa que eu mais quero é ter uma família feliz. Eu fico muito triste com meu pai fora de casa, com aquela mulher. Eu quero muito que ele volte pra mim, que ele volte pra casa. ("Pintor de Quadros" - criança colaboradora 09)

[...] Queria ser mais calminho, sem ter tanta raiva, tipo a pessoa perguntar se eu tô [sic] bem e eu conversar com aquela pessoa... ("Médico" - criança colaboradora 08)

Eu quero ser professor para ser mais inteligente. ("Professor" - criança colaboradora 07)

Em alguns discursos, aflorou o sentimento de constrangimento não apenas diante do estigma como também em relação às limitações próprias dos transtornos mentais:

Eu não gosto de tomar remédio, mas quando eu tomo, eu não fico com dor de cabeça. ("Piloto" - criança colaboradora 05 )

Para Marín (2009), o sofrimento é percebido como a falta de bem-estar. Lidar com ele, e até mesmo superálo, é possível através da capacidade interna de dar-lhe um sentido, extravasando os conteúdos negativos para encontrar alívio e esperança.

Quando eu fico com um pouco de raiva, (confuso), às vezes eu durmo, né? [...] Eu vou procurar coisa que me acalme. Às vezes eu gosto de conversar com minha mãe quando eu tô [sic] triste, com minha avó. Quando eu tô com raiva, vou ficar [sic] assistindo televisão, vou ficar [sic] de frente lá de casa. Quase sempre eu choro. ("Médico" - criança colaboradora 08)

No fragmento do relato a seguir, pode-se perceber que 
a estratégia encontrada pelo sujeito quando está triste é ter comportamentos agressivos e impulsivos, mas, após a descarga comportamental, somatiza com dores de cabeça:

Algumas vezes eu grito e bato. [...] Porque eles me batem. Os meninos da escola me batem... ("Professor" - criança colaboradora 07)

Por vezes, a única forma de extravasar os conteúdos negativos é por meio da expressão da agressividade, embora depois da liberação emocional surjam outros elementos negativos. Independentemente do acometimento, cada colaborador lidou com seu sofrimento de forma única, apesar da generalização de alguns sintomas. De todas as estratégias encontradas pelos colaboradores, a via mais salutar foi através do lúdico, ratificando o que fora supraexposto. Winnicott (1975) compreendia o brincar como uma simulação de situações do mundo adulto e estruturante da saúde psíquica, pois, através da espontaneidade da atividade lúdica, permeada por regras próprias, criatividade, alegrias e mesmo frustrações, é possível a construção de culturas internas, do contato com a realidade que a cerca, dos conflitos inerentes a estas vivências e descobertas, e da expressão dos desejos e das angústias.

\section{Considerações Finais}

Diante do que foi analisado nos discursos dos colaboradores, ficou patente a propriedade que cada um tem de retratar as percepções, vivências e enfrentamentos de seus sofrimentos psíquicos, independentemente da severidade de seus transtornos clínicos, idade ou desenvolvimento escolar.

A criança estava plenamente imersa na cultura adultocêntrica, na qual seu discurso sobre o que a afetava era negado, cabendo ao adulto a interpretação e compreensão do estado psicológico e físico do ser em estado de desenvolvimento. Validar cientificamente estas tessituras de subjetividade sob a ótica das crianças portadoras de tais dores anímicas é um avanço notável e próprio do contexto hodierno, no qual à criança das últimas décadas foi reservado um espaço atento de escuta de suas demandas subjetivas.

Neste aspecto, é possível apreender a relevância deste trabalho, na tentativa de compreender a criança que sofre de acometimento psíquico, pela ótica desta, de modo a sair da condição patológica e atingir a dimensão de inteireza, além de poder se tornar mais uma referência futura para novos estudos que tenham como foco principal o conhecimento sobre a saúde mental infantil a partir de suas narrativas vivenciais.

\section{Referências}

Albornoz, A. C. G., \& Nunes, M. L. T. (2004). A dor e a constituição psíquica. Psico/USF, 9(10), 211-218.

Alderson, P. (2005). As crianças como pesquisadoras: Os efeitos dos direitos de participação sobre a metodologia de pesquisa. Educação e Sociedade, 91(26), 419-442.

Antonio, M. C. A. (2006). Dores da alma: Etnografia do sofrimento psíquico em segmentos de camadas médias urbanas. Revista Urutágua, 10(3), 1-13.

Ariès, P. (1981). História social da infância e da família. São Paulo: Editora LTC.

Botelho, S. L. F., Janzen Kassab, S. L. F. S., \& Leite, M. L. (2008). Meninos de rua: Desafiliados em busca de saúde mental. Psicologia Estudos, 13(2), 361-370.

Bock, A. M. M., Furtado, O., \& Teixeira, M. L. T. (2000). Psicologias: uma introdução ao estudo de psicologia. São Paulo: Atlas.

Câmara, Y. M. R. (2011). Percepção, vivência e enfrentamento do sofrimento psíquico em crianças usuárias de CAPS infantil. Dissertação de Mestrado em Psicologia, Universidade Federal do Ceará, Fortaleza, CE, Brasil.

Cavalcante, F. (2001). Família, subjetividade e linguagem: Gramáticas da criança "anormal". Ciência e Saúde Coletiva, 6(1), 125-137.

Chvatal, V. L. S., Böttcher-Luiz, F., \& Turato, E. R. (2009). Respostas ao adoecimento: mecanismos de defesa utilizados por mulheres com síndrome de Turner e variantes. Revista de Psiquiatria Clínica, 36(2), 48-53.

Corsaro, W. A., \& Miller, P. J. (1992). Interpretative approaches to childrens socialization. In New directions for child development (pp. 5-23).

Delgado, A. C. C., \& Müller, F. (2005). Em busca de metodologias investigativas com as crianças e suas culturas. Cadernos de Pesquisa, 35(125), 161-179.

Del Priore, M. (2000). História das crianças no Brasil. São Paulo: Contexto.

Fadiman, J., \& Frager, R. (1994). Teorias da personalidade. Porto Alegre: Marbra.

Fontanella, B. J. B., Campos, C. J. G., \& Turato, E. R. (2007). Coleta de dados na pesquisa clínico-qualitativa: Uso de entrevistas não-dirigidas de questões abertas por profissionais da saúde. Revista Latinoamericana de Enfermagem, 14(5), 812-820.

Foucault, M. (1984). Vigiar e punir: Nascimento da prisão. 
Rio de Janeiro: Vozes.

Foucault, M. (1996). Microfisica do poder. Rio de Janeiro: Graal.

Gabel, M. (1997). Crianças vítimas de abuso sexual. São Paulo: Summus.

Kramer, S. (2002). Autoria e autorização: Questões éticas na pesquisa com crianças. Cadernos de Pesquisa, (116), 41-59.

Jovchelovitch, S., \& Bauer, M. W. (2003). Entrevista narrativa. In M. W. Bauer; \& G. Gaskell, Pesquisa qualitativa com texto, imagem e som: Um manual prático ( $2^{\mathrm{a}}$ ed.). Petrópolis: Vozes.

Laplanche, J., \& Pontalis, M. (1992). Vocabulário de psicanálise ( $2^{\mathrm{a}}$ ed.). São Paulo: Martins Fontes.

Marín, R. Z. (2009). La enfermedad y el sentido del sufrimiento. Revista Cubana Salud Pública, 35(1), 0-0.

Minayo, M. C. S. (2000). O desafio do conhecimento: Pesquisa qualitativa em saúde. São Paulo: Hucitec; Rio de Janeiro: Abrasco.

Müller, F. (2006). Infâncias nas vozes das crianças: culturas infantis, trabalho e resistência. Educação e Sociedade, 27(95), 553-573.

Papalia, D. E., \& Feldman, R. D. (2013). Desenvolvimento humano $\left(12^{\mathrm{a}}\right.$ ed.). Porto Alegre: Mc Graw Hill Artmed, AMGH Editora Ltda.

Resolução nº196/96 do Conselho Nacional de Pesquisas (CNS) (1996). Diretrizes e normas regulamentadoras de pesquisas envolvendo seres humanos. Ministério da Saúde. Brasília, DF.

Rocha, E. A. C. (2004). Crianças e infâncias: Uma categoria social em debate. Revista Zero a Seis, 6(9), 15-20.

Sarmento, M. J., \& Cerisara, A. B. (2004). Crianças e miúdos: Perspectivas sociopedagógicas da infância e educação. Porto: Asa.

Soares, A. H. R., Moreira, M. C. N., Monteiro, L. M. C., \& Fonseca, M. G. O. (2005). A enurese em crianças e seus significados para suas famílias: Abordagem qualitativa sobre uma intervenção profissional em saúde. Revista Brasileira de Saúde Materno-Infantil, 5(3), 301-311.

Solon, L. A. G. (2009). Conversando com crianças sobre adoção. São Paulo: Casa do Psicólogo Livraria e Editora.

Tommasi, M. C. F. (1997). O conceito de agressividade na obra de Winnicott. Infanto: Revista de Neuropsiquiatria da Infância e Adolescência, 5(2), 73-76.
Torralba, F. (2007). Aproximación a la esencia del sufrimiento. Anales Sistema Sanitario Navarra, 30 (supl. 3), 23-37.

Winnicott, D. W. (1975). O brincar e a realidade. Rio de Janeiro: Imago.

Winnicott, D. W. (1990). O ambiente e os processos de maturação: estudos sobre a teoria do desenvolvimento emociona ( $3^{\mathrm{a}}$ ed.). Porto Alegre: Artes Médicas.

Winnicott, D. W. (1994). Os bebês e suas mães. São Paulo: Editora Martins Fontes.

Winnicott, D. W. (1997). A família e o desenvolvimento individual. São Paulo: Editora Martins Fontes.

Endereço para correspondência:

Yzy Maria Rabelo Câmara

Endereço: Rua Vicente Nobre Macedo, $n^{\circ}$ 10, Messejana.

Fortaleza/CE. - CEP: 60841-110

E-mail: yzycamara@gmail.com

\section{Endereço para correspondência:}

João Joaquim Freitas do Amaral

Endereço: Rua Professor Costa Mendes, $\mathrm{n}^{\circ}$ 1608, Rodolfo Teófilo. Fortaleza/CE. - CEP: 60430-140

E-mail: joaoamaral@terra.com.br

\section{Endereço para correspondência:}

Yls Rabelo Câmara

Endereço: Calle Burgo das Nacións, ${ }^{0}$ 3014, Santiago de Compostela, La Coruña - España. - CEP: 15705

E-mail:ylscamara@hotmail.com 